\title{
Nüks gösteren odontojenik keratokist vakasında enükleasyon sonrası kriyoterapi uygulanması: olgu bildirimi
}

\section{Performing cryotherapy after enucleation in recurrent odontogenic keratocyst case: case report}

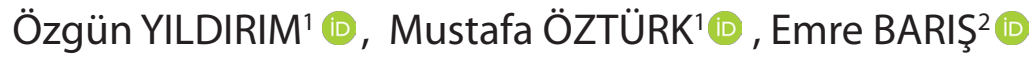 \\ ${ }^{1}$ Gazi Üniversitesi Diş Hekimliği Fakültesi Ağız, Diş ve Çene Cerrahisi AD, Ankara/TÜRKiYE \\ ${ }^{2}$ Gazi Üniversitesi Diş Hekimliği Fakültesi Oral Patoloji AD, Ankara/TÜRKIYE
}

\section{Öz}

Odontojenik keratokist; lokal agresif davranış, yüksek rekürrens oranı ve ayırıcı histolojik görünüm gibi özelliklere sahiptir. İlk olarak Philipsen tarafından 1956'da tanımlanmıştır. Odontojenik keratokist, dişlerin laminasından veya primordiyal odontojenik epitelden kaynaklanan iyi huylu, çenelerde uniloküler veya multiloküler kistik yapı şeklinde görülen, intraosseöz bir kist olarak tanımlanır. Hayatın ikinci ve dördüncü dekadlarında pik yapmakla birlikte her yaş grubunda görülebilir. Mandibulada görülme oranı maksillaya göre daha fazla olmakla beraber, mandibulada ortaya çıkan odontojenik keratokist vaka yüzdesi \%65-83 civarındadır. Mandibulada lezyonların çoğu posterior bölgede, angulusta ve yükselen ramusta görülür. Odontojenik keratokist tedavisi çoğunlukla; küretajlı/küretajsız enükleasyon, marsupyalizasyon, periferal osteotomi, Carnoy solüsyonu ile kimyasal küretaj, kriyoterapi, elektrokoter ve segmental rezeksiyon ile yapılır.Bu çalışmada, 50 yaşındaki erkek hastanın sağ mandibula ramus bölgesinde lokalize, nüks göstermesi nedeni ile iki sene üç ay sonra enükleasyonun ardından kriyoterapi uygulanan odontojenik keratokist vakası sunulmuştur. Nüks sonrası enükleasyon ile birlikte kriyoterapi kullanılarak opere edilen hastadan 9 ay sonra alınan panoramik radyografide yeni kemik oluşumu gözlenmiş ve nükse dair herhangi bir semptom saptanmamıştır.

Anahtar Kelimeler: Kriyoterapi; nüks; odontojenik kist.

\section{Abstract}

Odontogenic keratocyst has unique features such as local aggressive behavior, high recurrence rate and differential histological appearance. It was first described by Philipsen in 1956. Odontogenic keratocyst is defined as an intraosseous cyst, which is seen as a benign, unilocular or multilocular cyst in the jaws, which is caused by the lamina of the teeth or primordial odontogenic epithelium. It can be seen in every age group, although it peaks in the second and fourth decades of life. Although the incidence of mandibula is higher than maxilla, the percentage of cases in the mandible is $65-83 \%$. Most of the lesions in the mandible are seen in the posterior region, at the angulus and at the rising ramus. Odontogenic keratocyst treatment is usually performed by curettage / without curettage enucleation, marsupialization, peripheral osteotomy, Carnoy solution with chemical curettage, cryotherapy, electrocautery and segmental resection.In this study, a 50-year-old male patient was presented with odontogenic keratocyst who underwent cryotherapy after enucleation for two years and three months due to recurrence in the right mandibula ramus region.New bone formation was observed in the panoramic radiograph taken 9 months after the patient was treated using cryotherapy with enucleation after recurrence and no symptoms of relapse were detected.

Keywords: Cryotherapy; odontogenic cyst; recurrence.

Sorumlu Yazar*: Özgün Yıldırım, Gazi Üniversitesi Diş Hekimliği Fakültesi Ağız, Diş ve Çene Cerrahisi AD, Ankara/TÜRKiYE E-Posta: ozgunyldrm89@gmail.com

Gönderim:29.11.2019 Kabul: 22.02.2020

ORCID: 0000-0002-7974-1359

Doi:10.18663/tjcl.652910 


\section{Giriş}

Odontojenik keratokist(OK), dental lamina artıklarından ve diş formasyonu öncesinde gelişen mine organı benzeri primordial dokulardan kaynaklanan, odontojenik kökenli, benign, unikistik ve multikistik formları olan intraosseöz bir kisttir[1]. Bu lezyon, literatürde ilk kez 1876 yılında Mikulicz tarafından belirtilmiş olup, Philipsen tarafından 1956 yılında tanımlamıştır[1,2].

OK'leri diğer odontojenik kistlerden ayıran başlıca özellikleri; yüksek rekürrens oranına sahip olmaları, spesifik histopatolojik özellikleri ve agresif biyolojik davranışlarıdır[2]. Bu bahsedilen özellikleri nedeniyle OK'ler literatürde oldukça fazla yer edinmiştir. Bazı literatürlerde, kist epitelinin malign formasyonlara uğradığı ve ameloblastomaya dönüştüğü olgular takdim edilmiştir[3].

OKtedavisihala tartışmalıdır.Tedavilergenelliklekonvansiyonel ve agresif olarak sınıflandırılır. Konservatif tedavi çoğunlukla, küretajlı/küretajsız enükleasyonu ve marsupyalizasyonu içerir. Agresif tedavi ise genel olarak periferal osteotomi, Carnoy solüsyonu ile kimyasal küretaj, kriyoterapi, elektrokoter ve segmental rezeksiyonu içerir[4].

Kriyoterapi kelimesi, Yunanca "kriyos" (buz gibi, donmuş) ve terapi (tedavi) kelimelerinden türemiştir. Bu yöntemle lezyonlar dondurularak ortadan kaldırılmakta, fonksiyonel ve estetik olarak çok başarılı sonuçlara ulaşılmaktadır. Kriyoterapi günümüzde dermatoloji dışında tıbbın birçok alanında oldukça geniş bir uygulama alanı bulmaktadır. Kriyoterapide son yıllarda en çok sıvı nitrojen kullanılmaktadır. Kaynama noktası -195.6 santigrat derece olan likit nitrojen özellikle; benign ve malign kanserler, hemangiomlar, tonsillektomi, baş ve boyun cerrahisi, prostatektomi, Parkinson hastalığı ve hipofizektomide kullanılmaktadır[5].

Enükleasyon ile birlikte uygulanan likit nitrojen kriyoterapisi tekniğinin amacı, görünür patolojik dokuyu çıkarmak, nüksetmeye yol açabilecek olası hücreleri dondurup öldürmek ve nekrotize etmektir. Likit nitrojen, hücreleri nekrotize etme özelliğine sahiptir ve osteojenik ve osteokondüktif özellikleri tahrip eden Carnoy çözeltisinin aksine inorganik kemik yapılarını korur. Kriyoterapi tekniği çevre anatomik yapıları ve kemiği korur ve daha iyi onarım sağlar. Ayrıca kemiğin inorganik yapısını korur ve patolojik kırıkları önleme amacıyla derhal rekonstrüksiyon yapılabilmesine imkan sağlar[6].

\section{Olgu}

Diş ağrısı şikayeti ile Gazi Üniversitesi Diş Hekimliği Fakültesi'ne Başvuran 46 yaşındaki erkek hastadan alınan panoramik radyografide sağ mandibula angulus bölgesinde iyi sınırlı, radyolüsent lezyon tespit edilmiş olup hasta Ağız, Diş ve Çene Cerrahisi Anabilim Dalı́na yönlendirilmiştir [Resim 1]. Hastadan alınan anamnezde sistemik ve genetik bir hastalığının olmadığı öğrenilmiştir. Yapılan intraoral ve ekstraoral muayenelerde iltihap, ekspansiyon ve ağrı gibi herhangi bir klinik semptom tespit edilmemiştir. Kistik lezyonun lokal anestezi altında mukoperiosteal flep kaldırılarak enükle edilmesiyle elde edilen örnekler Gazi Üniversitesi Diş Hekimliği Fakültesi Oral Patoloji Anabilim Dalı'na gönderilmiştir. Histopatolojik incelemede yüzeyi parakeratinize, retesiz, bazal tabaka hücreleri çit tarzında dizilim gösteren odontojenik çok katlı yassı epitel ile döşeli kistik lezyona parakeratinize odontojenik keratokist tanısı konmuştur [Resim 2].

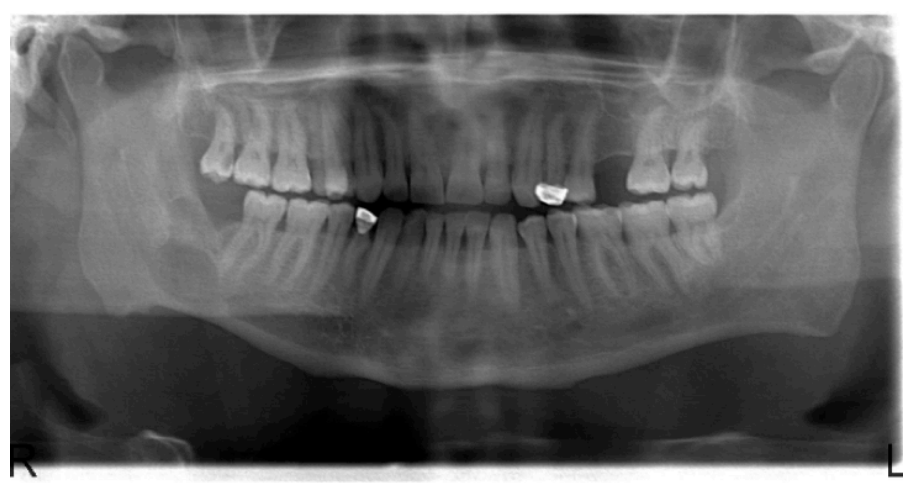

Resim 1. Hastanın ilk operasyondan önceki panoramik radyografisi

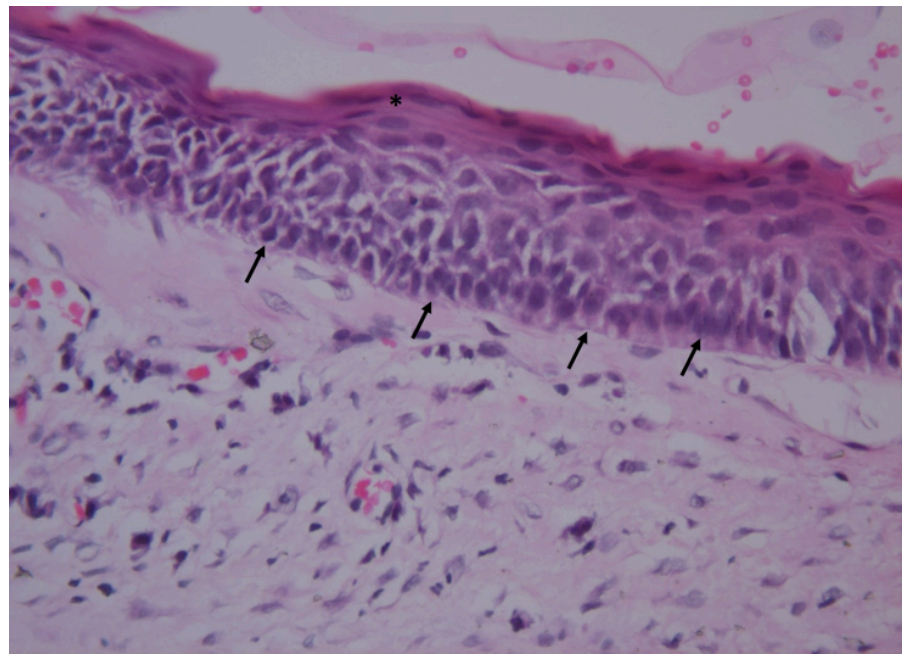

Resim 2. Yüzeyi parakeratinize $\left(^{*}\right)$ bazal tabaka hücreleri ters polarizasyona sahip (ok), retesiz odontojenik çok katlı yassı epitel ile döşeli kistik lezyon (HE x400) 
Operasyon sonrası kontrole gelmeyi ihmal eden hasta, ilgili bölgesinde ağrı meydana gelmesi nedeniyle 2 sene sonra kliniğimize yeniden başvurmuş ve alınan kontrol filminde lezyonun nüks ettiği ve boyutunun eskiye nazaran daha da büyüdüğü tespit edilmiştir [Resim 3]. Lokal anestezi altında gerçekleştirilen ikinci operasyonda; lezyona komşu 47 numaralı dişin çekiminin ardından ilgili bölgeden mukoperiosteal flep kaldırılarak,enükleasyon ve küretaj ile beraber nervus alveolaris inferioru koruma maksadıla kist kavitesinin tabanı hariç yalnızca duvarlarınalikit nitrojen kriyoterapisiuygulanmıştır.Íkinci ameliyat materyali de parakeratinize OK tanısı alan hastadan 9 ay sonra alınan kontrol filminde sağlıklı yeni kemik oluşumu gözlenmiş olup herhangi bir semptom saptanmamıştır [Resim 4].

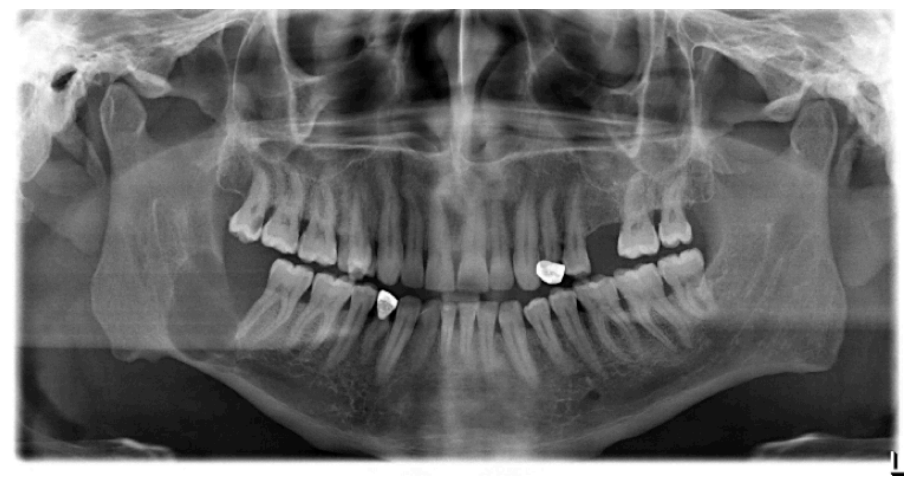

Resim 3. Hastadan 2 sene sonra alınan panoramik radyografi

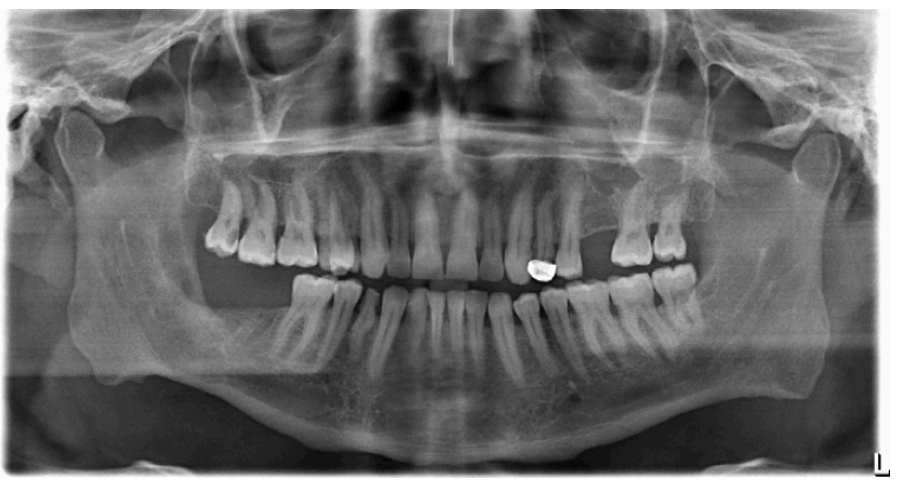

Resim 4. Hastanın enükleasyon sonrası kriyoterapi uygulanarak yapılan ikinci operasyondan sonraki panoramik radyografisi

\section{Tartışma}

OK birçok benzersiz klinik ve histolojik özelliğe sahip; iyi huylu, gelişimsel bir odontojenik kisttir[7]. OK'nin genişbir görülme yaş aralığı vardır, ancak çoğunlukla yaşamın ikinci ve dördüncü dekatlarında görülür.Bu lezyonlar erkeklerde daha sık görülür[8]. Vakaların \%70'inden fazlası, özellikle mandibuler molar, ramus ve angulus bölgelerinde görülür[9].
Mandibulada görülme oranı maksillaya göre daha fazla olmakla beraber, mandibulada ortaya çıkan OK vaka yüzdesi \% 65-83 civarındadır. Bu lezyon, mandibulada herhangi bir bölgede meydana gelebilir; ancak lezyonların çoğu posterior bölgede, angulusta ve yükselen ramusta görülür[10]. Maksilla anterior, maksiller sinüs ve maksiller posterior gibi diğer bölgelerde görüldüğü de bildirilmiştir[9].OK'ler ve diğer çene kistleri arasındaki temel farklardan biri, OK'nin medüller kemik içinde sinsice büyümesi ve klinik semptomlara neden olmamasıdır[7]. Sunulan bu çalışmadaki hasta 46 yaşında erkektir ve lezyon mandibula sağ ramusta tespit edilmiştir. illk operasyondan sonra kontrole gelmeyen hasta, ağrısının olmasından dolayı hastanemize 2 sene sonra tekrar başvurmuş ve lezyonun nüks ettiği tespit edilmiştir.

OK, dental lamina hücrelerinden gelişir. Histopatolojik olarak OK, tipik olarak tek parça halinde kemikten enükleasyonu zor olan ve lifli, içinde küçük uydu kistleri bulunan, ince ve fibröz bir kist epitel duvarı içerir. Bu nedenle OK'ler genellikle tedaviden sonra nüks etme eğilimindedir[11]. Bu lezyonların nüks oranlarının \%2.5 ile \%62.5 arasında olduğu ayrıca multiple odontojenik keratokistlerin Nevoid Bazal Hücreli Karsinoma Sendromu (NBHKS) ile ilgili olabileceği de literatürlerde sunulmuştur[12]. Yapılan histopatoloik inceleme sonucu lezyona parakeratinize odontojenik keratokist tanısı konmuştur.

OK'ler; epitelyal kökenli kistler olup, çenelerde görülen kistlerin yaklaşık \%11'ini oluşturmaktadır. Bu kistler çenelerde görülen birçok kist ve tümör gibi çenelerde ekspansiyon yapmadan ve bulundukları bölgede enfeksiyona sebebiyet vermeden hastalar tarafindan farkedilmezler. Ekspansiyon konusundaki en kritik belirteç, kemikte yaptığı ekspansiyonun, alınan radyograflarda tespit edilen boyutlarına göre çok daha az miktarda olmasıdır[13]. Radyografik olarak OK, düzgün ve sıklıkla kortikal kenarlara sahip iyi izlenebilen uniloküler veya multiloküler görünüm sergiler[11]. Bu lezyonlar, kemiğin medüller kavitesi içinde hastanın rahatsızlık duyacağı herhangi bir semptoma sebebiyet vermeden, çoğu kez dışardan gözlenebilecek ekspansiyona sebep olmadan, antero posterior yönde büyüme eğilimindedirler[7,11,14]. Bizim vakamızdan alınan panoramik radyografilerde lezyon uniloküler ve iyi sınırlı olarak tespit edilmiştir. Ekspansiyon ve enfeksiyon bulgusu yoktur. Lezyonun nüksü tespit edilene kadar geçen sürede anetro posterior yönde geniş̧lediği tespit edilmiştir. 
OK'ler için çeşitli tedavi seçenekleri tanımlanmıştır. Walid Ahmed Abdullah 2011 yılında bir çalışmasında,OK'lerin cerrahi tedavisini; dekompresyon ve marsupyalizasyon, tek başına ya da başka yardımc uygulamalarla enükleasyon, enükleasyon ve Carnoy solüsyonu ile kemik defektinin tedavisi, enükleasyon ve sıvı nitrojen kriyoterapisi, çenenin devamlılığını koruyarak ya da bozarak uygulanan blok rezeksiyon olarak sınıflandırmıştır[11]. Tedavi; lezyonun ilgili bölgede ortaya çıkmasından itibaren geçen süre, yeri ve büyüklüğü gibi bazı faktörlere ve lezyonun primer olması veya nüks etmesi durumuna bağlıdır. "Periferik ostektomi" ile total enükleasyon, lezyon tekrarlamadıkça veya önemli yumuşak doku invazyonu olmadıkça, çoğu OK için tercih edilen tedavi yöntemidir[15]. Sunduğumuz hastanın tedavisinde enükleasyon ve likitnitrojen kriyoterapisi yönemini tercih ettik ve 9 ay sonra alınan kontrol filminde başarılı sonuç aldığımızı kaydettik.

OK tedavisi için enükleasyondan sonra kemik duvarlarına kriyoterapi uygulanması ilk olarak 1975 yılında Bradley ve Fisher tarafından tanımlanmıştır[16]. Yapılan bir çalışmada 139 OK vakasının \%25'inin uydu kisti içerdiği bildirilmiştir[17]. Kriyoterapi uygulanarak kemik doku içerisinde kalan epitel artıklarının ve uydu kistlerinin dondurularak öldürülmesi amaçlanmaktadır[12].

Zhou ve arkadaşlarının 2006 yılında yaptıkları bir çalışmada, rekürrens gösteren 10 hastaya, enükleasyon yöntemi ile birlikte likit nitrojen içeren kriyoterapi yapıldığı ve 5 yıllık hasta takiplerinde hiçbir vakada nüks görülmediği rapor edilmiştir[18].

Schmidt ve Pogrel'in 2001 yılında yayınladıkları bir çalışmada, OK'i olan 26 hastayı enükleasyon ve likit nitrojen kriyoterapisi ile tedavi ettikleri ve rekürrensin yalnızca 3 hastada (\%11.5) görüldüğü bildirilmiştir[19].

Ayrıca Eduardo Luis de Souza Cruz ve arkadaşları 2017 yılında yayınladıkları bir çalışmada; propan, bütan ve izobütan gaz karışımına sahip kriyoterapiyi, sıvı nitrojene alternatif olarak göstermişler ve OK tanısı alan 10 hastanın 8'inde başarılı sonuç aldıklarını ve nüks gözlemediklerini bildirmişlerdir. Hastaların hiçbirinde patolojik fraktür ve enfeksiyon görülmemiştir[20].

\section{Sonuç}

Mandibula ramus bölgesinde lokalize, nüks göstermesi nedeni ile iki sene üç ay sonra enükleasyonun ardından kriyoterapi uygulanan odontojenik keratokist vakası sunulmuştur. Nüks sonrası enükleasyon ile birlikte kriyoterapi kullanılarak opere edilen hastadan 9 ay sonra alınan panoramik radyografide yeni kemik oluşumu gözlenmiş ve nükse dair bir semptom saptanmamıştır.

\section{Çıkar çatışması / finansal destek beyanı}

Bu yazıdaki hiçbir yazarın herhangi bir çıkar çatışması yoktur. Yazının herhangi bir finansal desteği yoktur.

Teşekkür ve Anma: Bu vaka, aynı yazarlar tarafından Türk Oral ve Maksillofasiyal Cerrahi Derneği 24. Uluslararası Bilimsel Kongresi'nde poster bildirimi olarak sunulmuştur.

\section{Kaynaklar}

1. Alan H, Küçük AÖ, Yolcu Ü, Aydın NE. Bir hastada eş zamanlı keratokistik odontojenik tümör ve radiküler kist oluşumu: Olgu sunumu. Mersin Üniv Sağlık Bilim Derg. 2018;11:383-88.

2. Duman ŞB, Yaşa $Y$, Ocak A. Keratokistik odontojenik tümör: panoramik, tomografik ve ultrasonografik değerlendirme. EÜ Dişhek Fak Derg. 2015; 36:52-55.

3. Özgenel GY, Özbek S, Akın S, Kahveci R. Üç Kuşakta Görülen Odontojenik Keratokist. Turk Plast Surg. 2010;18: 116-19.

4. Akay C, Tetik A, Zeytinoğlu M. Keratocystic odontogenic tumor: A retrospective study of 64 cases. Ege J Med. 2015; 54:59-64.

5. Tarım G, Cantürk T, Şentürk N, Turanlı AY. Dermatolojik tedavide kriyoterapi kullanımı. OMÜ Tıp Derg 2000;17: 210-12.

6. Tonietto L, Borges HOI, Martins CAM, Silva DN, Filho MSA. Enucleation and liquid nitrogen cryotherapy in the treatment of keratocystic odontogenic tumors: a case series. J Oral Maxillofac Surg. 2011;69: 112-17.

7. Okkesim A, Adışen Mz, Mısırlıoğlu M, Tekin U. Diagnosis and treatment of keratocystic odontogenic tumor mimicking a dentigerous cyst in panaromic radiography. Turk J Clin Lab 2017; 8:28-31.

8. Junior JLL, Ribeiro ED, Junior ESH, Araujo TN, Goes KKN, Aragao MS. Odontogenıc keratocyst of mandible. Ind J Otolaryngol Head Neck Surg.2006;58: 373-75.

9. Janardhan A, Prakash P, Prabhakar R. Odontogenic Keratocyst Associated With Impacted Maxillary Third Molar. Oral Surgery. 2013;1:50-52.

10. Mathew AK, Shenai P, Chatra L, Veena KM, Rao PK, Prabhu RV. Keratocystic odontogenic tumor in the mandible - an unusual case report. J ContempMed 2013;3:45-48.

11. Abdullah WA. Surgical treatment of keratocystic odontogenic tumour: A review article. The Saudi Dental Journal. 2011;23:61-65. 
12. Kocakahyaoğlu B, Çetiner S. odontojenik keratokistlerin tanı ve tedavisinde güncel yaklaşımlar. GÜ Diş Hek Fak Derg 2007;24 119-23.

13. Özan F, Yeler H, Göze ÖF. Parakeratotik tip odontojenik keratokist: vaka raporu. Atatürk Üniv Diş Hek Fak Derg2006;81-84.

14. Thermadam TP, Chatra L, Shenai P, Veena KM, Rao PK, Prabhu RV. Keratocystic Odontogenic Tumor - A Diagnostic Dilemma. J Contemp Med 2013;3: 209-13.

15. Bhat S, Babu SG, Shetty SR, Madi M, Nambiar S. Keratocystic odontogenic tumour occuring in an unusual location. Cukurova Med J2017;42:363-65.

16. Bradley PF, Fisher AD. The cryosurgery of bone an experimental and clinical assessment. Br J Oral Maxillofac Surg1975;13: 111-27.
17. James GJ, Whear NM. K-Y jelly as an aide to cryotherapy in the management of odontogenic keratocysts. Br J Oral Maxillofac Surg 2004;42:158-159.

18. Zhou J. Treatment of recurrent odontogenic keratocyst with enucleation and cryosurgery: a retrospective study of 10 cases. Shanghai Kou Qiang Yi Xue.2005;14: 476-78.

19. Schmidt B. The use of liquid nitrogen cryothe rapy in the management of odontogenic keratocyst. Oral Maxillofac Surg Clin North Am2003;15:393-405.

20. Cruz ELS, Tabosa AKS, Falcão ASC et al. Use of refrigerant spray of a propane/butane/isobutane gas mixture in the management of keratocystic odontogenic tumors: a preliminary study. Oral Maxillofac Surg. 2017;21:21-26. 